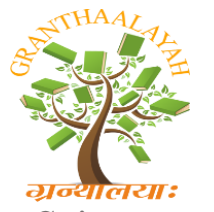

Science

\section{INTERNATIONAL JOURNAL OF RESEARCH - GRANTHAALAYAH A knowledge Repository}

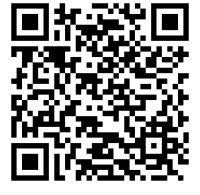

\title{
PREVELENACE OF LOW BACK PAIN AMONG NURSES WORKING IN ELMAK NIMER UNIVERSITY HOSPITAL - SHENDI - SUDAN 2015
}

\author{
Muaadh Abdulghani Ghaithan Al-samawi ${ }^{1}$, Higazi Mohammed Ahmed Abdallah Awad ${ }^{* 2}$ \\ ${ }^{1}$ Shendi University, SUDAN \\ ${ }^{* 2}$ Faculty of Nursing Science, Shendi University, SUDAN
}

\begin{abstract}
Globally, Low Back Pain (LBP) comprises a significant occupational hazard in nursing profession. Objectives: To estimate the incidence, to identify risk factors, and impact of illness of LBP among nurses in AL-Mak Nimer university Hospital at Shendi city.

A cross-sectional study was applied including nurses in AL-Mak Nimer university Hospital at Shendi city, republic of Sudan throughout the period May -June, 2015. Sample was chosen by using total coverage sample. A predesigned questionnaire was used for data collection. The questionnaire included demographic data, work-related factors as well as effect and management of LBP data obtained were analyzed using manually and by used SPSS soft program. Results: The results revealed that the overall incidence of low back pain among nurses was ( $n=70,87.5 \%)$ Female participants complaining of LBP were significantly more than male participants (85\%) of the total female reported $\mathrm{LBP}$. There were significantly relate between age and working hours (.015) it can be seen that about (40\%) of the participants experienced LBP at least once a week or more frequently. $52.9 \%$ subjects rated their pain as moderate pain. $35.7 \%$ nurses' concept regarding factors contributing to their LBP were lifting as well as $28.6 \%$ working load,(52.9\%) sleep disturbance, (64.3\%) restrict activities were nurse comment regarding $L B P$ effect.

LBP is a common health problem among working nurse, lifting, work load, were the most perceived work-related risk factors for LBP, restrict activities, taking many days off, might be the most predisposed effect related to LBP. Recommendation: These findings suggest that hospitals should focus and attempt to improve the ergonomics of nursing activities. In addition, effective methods of implementing changes in work systems are needed.
\end{abstract}

Keywords:

Low Back Pain, nurses, hospitals.

Cite This Article: Muaadh Abdulghani Ghaithan Al-samawi, and Higazi Mohammed Ahmed Abdallah Awad, "PREVELENACE OF LOW BACK PAIN AMONG NURSES WORKING IN ELMAK NIMER UNIVERSITY HOSPITAL - SHENDI - SUDAN 2015” International Journal of Research - Granthaalayah, Vol. 3, No. 9(2015): 108-121. 


\section{INTRODUCTION}

Low back pain is neither a disease nor a diagnostic entity of any sort. The term refers to pain of variable duration in an area of the anatomy afflicted so often that it is has become a paradigm of responses to external and internal stimuli. It is one of the most common cause of musculoskeletal disorder related to work status and condition. It occurs in similar proportions in all cultures, interferes with quality of life and work performance, and is the most common reason for medical consultation (Keriri ,2013).In Europe, $30 \%$ of the general worker population suffers from LBP. It remains the leading cause of disability in persons younger than 45 years old. More than one-quarter of the working population is affected by LBP each year with a lifetime prevalence of 60-80\% and a large percentage of LBP claims for long durations (more than 90 workdays lost). (Keriri ,2013) In the past decades, there has been increasing interest in occupational health issues relating to musculoskeletal system. One of these is low back pain (LBP), a phenomenon with particularly high prevalence all over the world, Low back pain is not only considered to be the most common reason for functional disability, worldwide, but also estimated to affect almost $90 \%$ of the universal population. Moreover, low back pain is said to be among the leading musculoskeletal disorders that predominantly affect the working population in developed as well as in developing countries. (Hinmikaiye and Bamishaiye ,2012). The etiology of LBP among nurses is usually multifactorial; probably because the job demands in nursing is a mixture of physically (such as manual handling of patients) and mentally demanding tasks (such as dealing with crises). However, it is usually difficult to separate the perception of mental and physical demands within the same (tasks ElNajjar, El-Fattah et al. (2014).

Poor working conditions have been implicated as a causative factor of LBP in nurses. Nurses in hospital wards are often faced with a lot of unplanned work with numerous and varied tasks and responsibilities. There is a strong association between LBP in nurses and postures in physical work such as lifting of heavy objects or transferring patients and equipment. Nurses are one of the few professional groups who have to work in shifts during their careers. Work shift implies either longterm night work or work involving rotation between day, evening, and night shifts. This may result in sleep disturbances, fatigue, and impaired work performance and safety awareness ("El-Najjar, El-Fattah et al. 2014).

It has been observed that individuals suffering from LBP might develop major disruptions in their physical, social, and mental well-being, which could affect their occupations. Physical impact includes the loss of physical function and deteriorated general health. Social impact includes decreased participation in social activities. Psychosocial impacts are manifested through insomnia, anxiety, and depression (El-Najjar, El-Fattah et al. 2014).

Prevalence and risk factors of low back pain among nurses in a typical done by (Sikiru L, Hanifa S) Four hundred and eight respondents (148 [36.27\%] males and 260 [63.73\%] females) participated in the study. The 12 month prevalence of LBP was 300 (73.53\%). LBP was more prevalent among female nurses $(68 \%)$ than the male nurses $(32 \%)$. It was also associated with occupational hazard and poor knowledge of back care ergonomics.A study of work stress, patient handling activities and the risk of low back pain among nurses in Hong Kong done by (bing Yip, Yin) Results. Of the 377 nurses interviewed, 153 (40.6\%) reported having LBP within the last 12 months. With symptoms of LBP as the outcome, risks were increased where nurses self-reported 
that they only occasionally or never enjoyed their work [adjusted odds ratio (OR) 2.07], where frequent manual repositioning of patients on the bed was required (adjusted OR 1.84) and where they were required to assist patients while walking (adjusted OR 2.11) after adjustment for other potential confounders.

The Incidence of Low Back Pain among Theatre Nurses (Hinmikaiye, C., and E. Bamishaiye.")Result : A response rate of $91 \%$ was obtained. Descriptive statistics were employed to summarize the demographic data of the study sample, which were presented using frequency tables and expressed as percentages, means and standard deviations. 57 (78.1\%) respondents experienced the first episode of back pain after commence nursing, more females $(70 \%)$ than males (30\%) were employed.It can be seen that about 44 out of 57 subjects who had experienced back pain in their career experienced it at least once a month or more frequently. $64.91 \%$ subjects rated their pain as moderate pain. The largest single category was 'low back', with $77.19 \%$ of the 57 analyzable responses. 34 respondents said they Lift patient within bed without assistance.

\section{Low back pain:}

Low back pain or lumbago is a common musculoskeletal disorder affecting $80 \%$ of people at some point in their lives. In the United States it is the most common cause of job-related disability, a leading contributor to missed work, and the second most common neurological ailment - only headache is more common. (ww.wikipedia.org /Low back_pain)

\section{Low Back Pain Definition:}

The term low back pain refers to pain in the lumbosacral area of the spine encompassing the distance from the 1st lumbar vertebra to the 1 st sacral vertebra. This is the area of the spine where the lordotic curve forms. The most frequent site of low back pain is in the 4th and 5th lumbar segment. It can be either acute, sub acute or chronic in duration. With conservative measures, the symptoms of low back pain typically show significant improvement within a few weeks from onset (ww.wikipedia.org/Low_back_pain).

\section{Low Back Pain Symptoms:}

With conservative measures, the symptoms of low back pain typically show significant improvement within a few weeks from onset, these lower back pain symptoms include any combination of the following: Difficulty moving that can be severe enough to prevent walking or standing. Pain that does not radiate down leg or pain that also moves around to the groin, buttock or upper thigh, but rarely travels below the knee. Pain that tends to be achy and dull. Muscle spasms, which can be severe. Local soreness upon touch (Peter F. Ullrich, Jr., 2012)

\section{Management:}

Avoid activities that may strain the back until healed, but bed rest is to be avoided as well because it may significantly decrease the rate of recovery, increase pain and disability, and lengthen time spent absent from work. When in bed, sleep in a supine to semi-Fowler's position with hips and knees flexed to relieve painful muscle and ligament sprain, heal soft-tissue injury, remove stress from lumbar sacral area, relieve tension on sciatic nerves, and open the posterior part of the intervertebral spaces. Acute spasm and pain should subside in 3 to 7 days if there is no nerve involvement or other serious underlying disease. Isometric exercises should be done hourly while in bed, if possible. Heat or ice used to relax muscle spasm and relieve discomfort. Follow heat 
with Massage. Medications. Oral analgesic and anti-inflammatory agent usually NSAID is firstline agent, unless contraindicated due to history or high risk of GI bleeding, renal insufficiency, or allergy. If there is a high risk of GI bleeding, COX-2 inhibitors may be used unless the patient has a sulfa or aspirin allergy, or is in the third trimester of pregnancy. Painful trigger points may be injected with hydrocortisone/Xylocaine for pain relief. Pain may be treated with opioid when severe. Opioids may be sedating. Muscle relaxant to relieve spasm/tense muscles. Muscle relaxants may be sedating. Lumbosacral support may be used "provides abdominal compression and decreases load on lumbar intervertebral disks. TENS may be helpful in relieving chronic pain. Psychiatric intervention may be needed for patient with chronic depression, anxiety, and lower back syndrome. Psychotropic medication may be used for treatment of depression and anxiety, which potentiate pain. (Lippincott Williams, 2010).

\section{Nurse Education and Health Maintenance}

Almost everyone has lower back pain at some time. Chronic pain will develop in some, and a few will become disabled because of it. Risk factors for chronic lower back pain include being overweight, being deconditioned (out of shape), having poor posture, and having poor abdominal muscle tone. You can relieve pain and avoid disability by adhering to the following instructions. Standing, sitting, lying, and lifting properly are necessary for a healthy back. Alternate periods of activity with periods of rest. Avoid prolonged sitting (intradiskal pressure in lumbar spine is higher during sitting), standing, and driving.

- Change positions and rest at frequent intervals.

- Avoid assuming tense, cramped positions.

- Sit in a straight-back chair with the knees slightly higher than the hips. Use a footstool if necessary.

- Flatten the hollow of the back by sitting with the buttocks tucked under. Pelvic tilt (small of back is pressed against a flat surface) decreases lordosis.

- Avoid knee and hip extension. When driving a car, have the seat pushed forward as necessary for comfort. Place a cushion in the small of the back for support.

When standing for any length of time, rest one foot on a small stool or platform to relieve lumbar lordosis. Avoid fatigue, which contributes to spasm of back muscles. Use good body mechanics when lifting or moving about. Daily exercise is important in the prevention of back problems.

- Do prescribed back exercises twice daily strengthens back, leg, and abdominal muscles.

- Walking outdoors (progressively increasing distance and pace) is recommended.

- Reduce weight if necessary decreases strain on back muscles. (Lippincott Williams, 2010).

\section{OBJECTIVES}

\section{General Objective:}

To determine the incidences of low back pain among nurses.

\section{Specific Objectives:}

- To identify the incidence of low back pain according to socio demographic status.

- To estimate the risk factors of low back pain.

- To identity the impacts of low back pain on nurses lives. 


\section{MATERIAL \& METHODOLOGY}

\section{Study Design:}

The was descriptive cross sectional hospital study .done to determine incidence of LBP among nurses in Shendi city in El - mak Nimer university hospital, in period extended from May to June 2015

\section{Study Area:}

The study was done in Shendi town which is located in $172 \mathrm{~km}$ to Khartoum city Shendi locality is one of the localities of the River Nile State. It is bounded by Khartoum state to the south, Elddamer locality to the north, River Nile to the west and Kassala state to the east.

Culturally the population of Shendi is a mixture of the various cultures that occur in Sudan though the Northern tribes, particularly ElGaalien, are predominant. Shendi University was established in the early 1990s and includes (10) faculties in the locality (Shendi, mattama, taybat elkhound).

The Shendi has university called Shendi University with different faculties and has two big hospital; teaching hospital and El - mek Nimer university hospital.

\section{Setting:}

This study was conducted in The Elmek Nimer university hospital, which was established in 2002 and has general units of medicine, surgery, pediatrics, obstetric, oncologic and others units.

\section{Study Population:}

The study involves all age groups of nurses in ELMAKNEMAR hospital during study period.

\section{Exclusion Criteria:}

- New graduate nurse.

- Not registered nurse

\section{Sampling Technique:}

Total converge sample.

\section{Sample Size:}

Eighty nurses were included in this study, from (121) nurse working in the hospital.

\section{Data Collection Tools:}

The data was collected by stander structured interview sheet with closed ended questions, designed by researcher based on reviewing of literature, it consist of three section the first section contain, question designed to collected demographic data, the second section, question designed to evaluate the prevalence of low back pain of the participant related risk factors associated with, and third section, question designed to addressed effect of LBP on participant and how they are deal with.

\section{Data Collection Technique:}

In this study the data was collected in one week, pre-designed questionnaire was used for data collection. 


\section{Data Analysis Technique:}

The collected data coded manually, organized, categorized, and tabulated in tables using frequencies and percentage. And using also soft program the statistical package for social sciences (SPSS version 19.0) was used for statistical analysis.

\section{Ethical Consideration:}

The permission has been approved from faculty board of research to conduct the study, a written permission was taking from original director of hospital then also permission was taken from the head nurse of each department. The purpose of the study was explained verbally and clearly in simple Arabic or English language to the nurses and then verbal consent has been taken from each nurses and they told they have right to withdrawal from this study when they need .

\section{Limitation:}

- We cannot ensure the honesty of the participants which can potentially exert an influence on the results

- The data are descriptive cross-sectional so that causal relations are subjected to interpretation.

- The response rate may be differs across the different departments in hospital.

- By implying this study for private hospitals \& comparing between them will give obvious difference images \& more information.

\section{RESULTS}

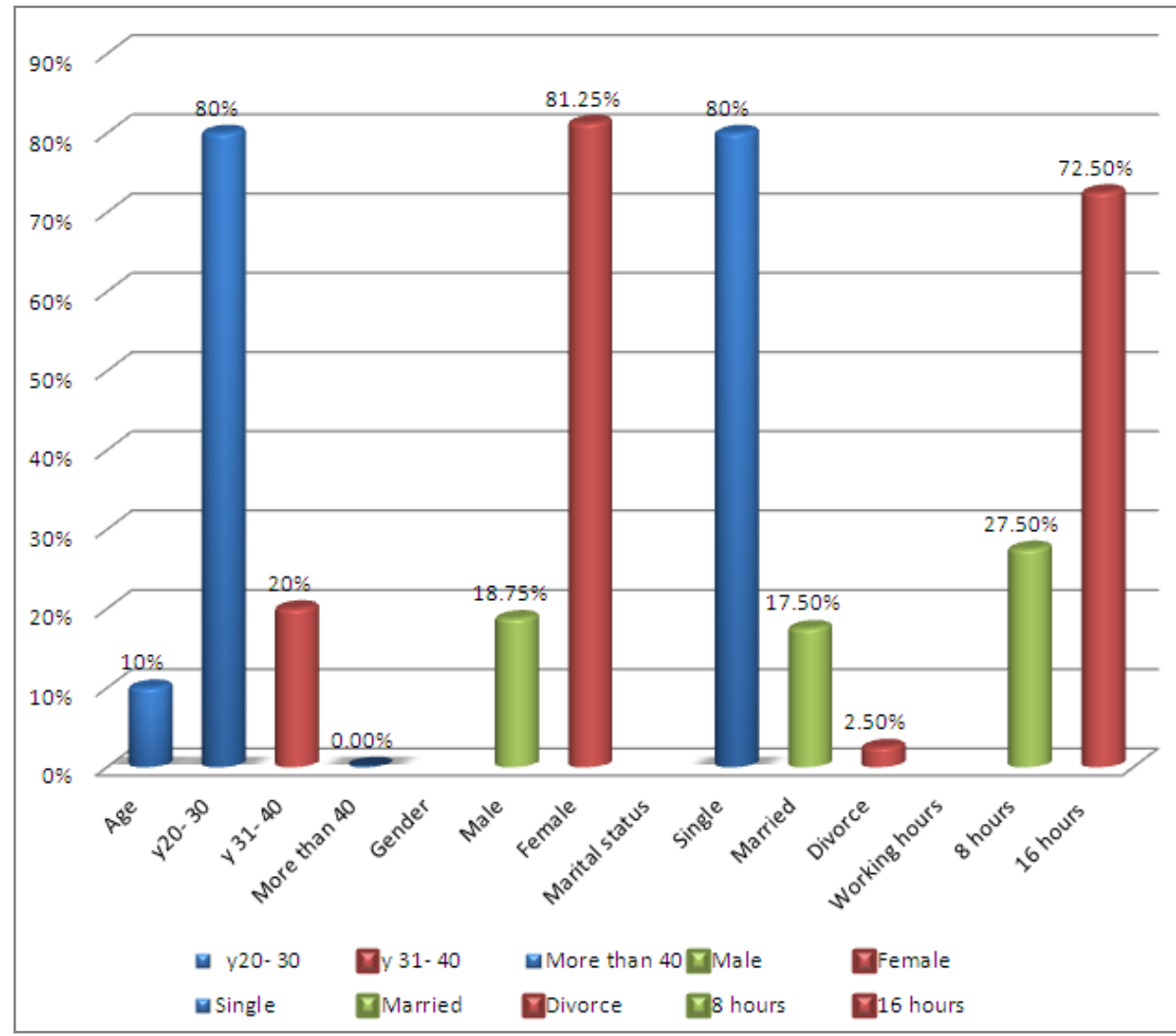

Figure 1: According to demographic data: 


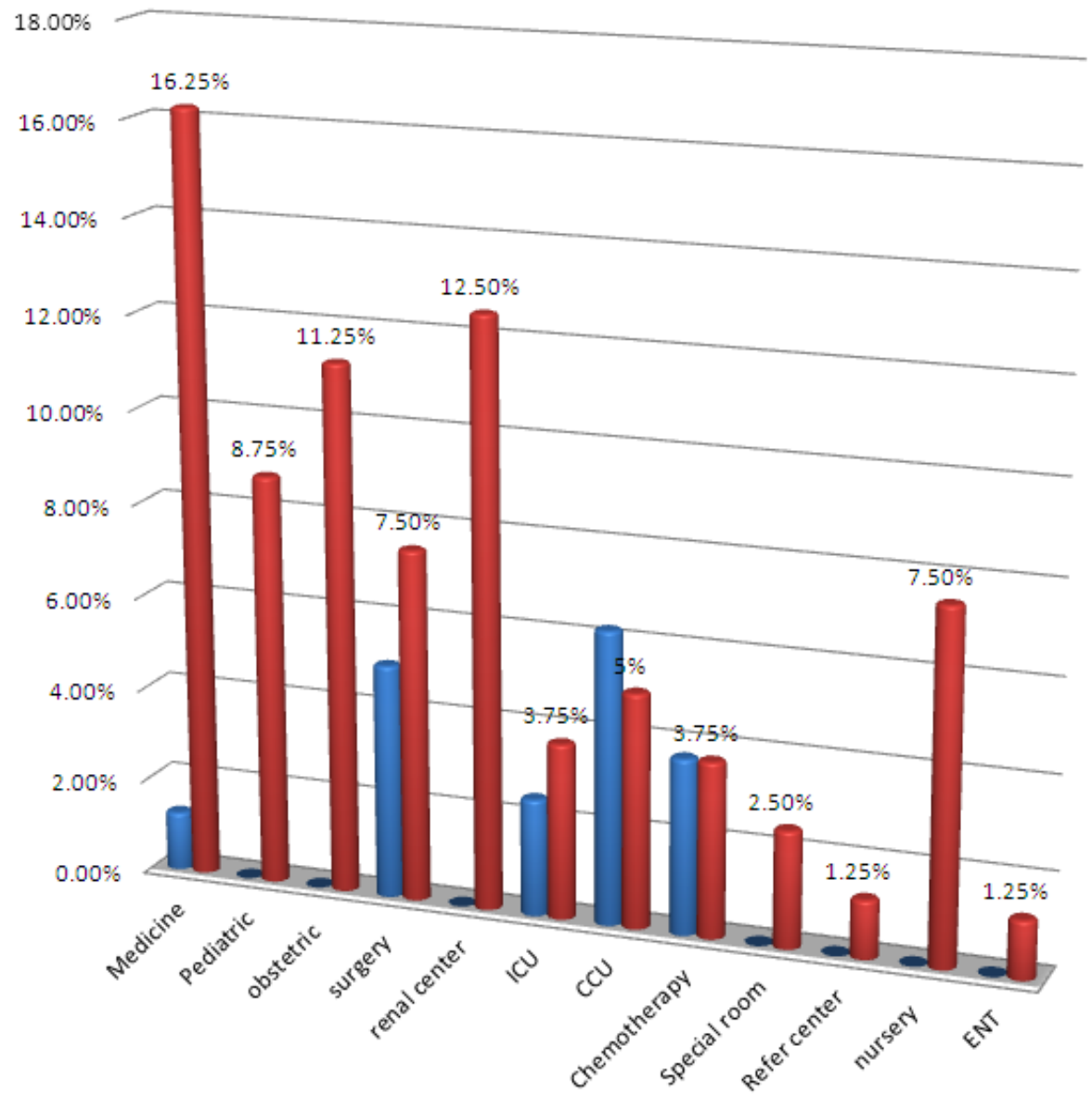

Figure 2: According To Department

Figure (1) showed that, The percentage Distribution of study group according to their demographic data: males in the sample were $(18.75 \%)$ and females were $(81.25 \%)$, The age between $(20-30)$ was $80 \%$ while age between(31-40) was (20\%). The single nurses in the sample was $(80 \%)$, married nurses( $17.50 \%)$ while divorce nurses were (2.50\%). Most of the nurse work about 16 hours per day and the rest of them work 8 hours per day, percentage were $(72.50 \%),(27.50 \%)$ respectively.

Figure (2) showed that, Distribution of study group according to their department in the time of data collection- were medicine (male $1.25 \%$ female $16.25 \%$ ), obstetric ( female $11.25 \%$ ), pediatric ( female $8.75 \%$ ), surgery (male 5\% female $7.5 \%$ ), ICU (mal 2.5\% female 3.75\%),CCU (male $6.25 \%$ female $5 \%$ ), renal dialysis (female 12.5\%), ENT (female 1.25\%), chemotherapy(male $3.75 \%$ female $3.75 \%$ ), refer(female $2.5 \%$ ), special room (female $2.5 \%$ ), nursery (female $7.5 \%$ )

Table 1: The distribution of study group according to smoking behavior:

\begin{tabular}{|l|l|l|}
\hline Smoking behavior & Frequency & Valid percent \\
\hline Never & 75 & $93.75 \%$ \\
\hline Current smoker & 5 & $6.25 \%$ \\
\hline Previous smoker & zero & $0.0 \%$ \\
\hline Total & 80 & $100.0 \%$ \\
\hline
\end{tabular}


Table (1) showed that, majority of nurses (93.75\%) never smoke, $(6.25 \%)$ current smoker and $(0.0 \%)$ previous smoker.

Table 2: Frequency percentage of incidence of lower back pain among the study group:-

\begin{tabular}{|l|l|l|}
\hline LBP & Frequency & Valid percent \\
\hline Never & 10 & $12.5 \%$ \\
\hline Sometime & 43 & $53.75 \%$ \\
\hline Always & 13 & $16.25 \%$ \\
\hline rarely & 14 & $17.5 \%$ \\
\hline Total & 80 & $100.0 \%$ \\
\hline
\end{tabular}

Table (2) showed that, less than quarter of nurses (12.5\%) never having LBP, more than half $(53.75 \%)$ sometime, $(16.25 \%)$ always, and less than quarter $(17.5 \%)$ rarely having LBP.

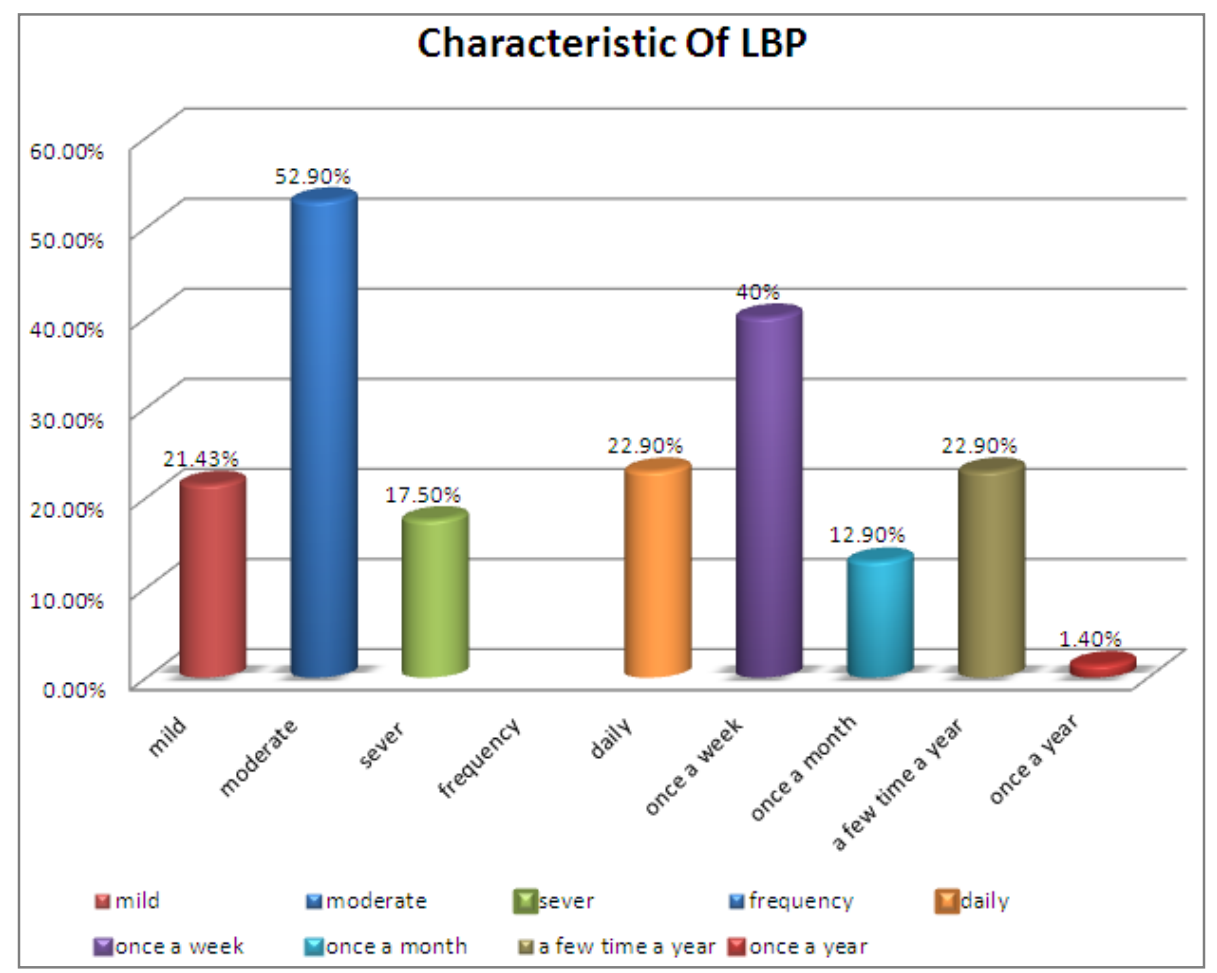

Figure 3: Characteristic of LBP:

Figure (3) showed that, characteristic of LBP, less than quarter of nurses (21.43\%) experience mild LBP, more than half $(52.9 \%)$ moderate, and less than quarter (17.5\%) Sever, less than quarter $(22.9 \%)$ is having daily LBP, $(40 \%)$ once week, less than quarter (12.9\%) once month, and (1.4 $\%$ ) having once a year LBP. 


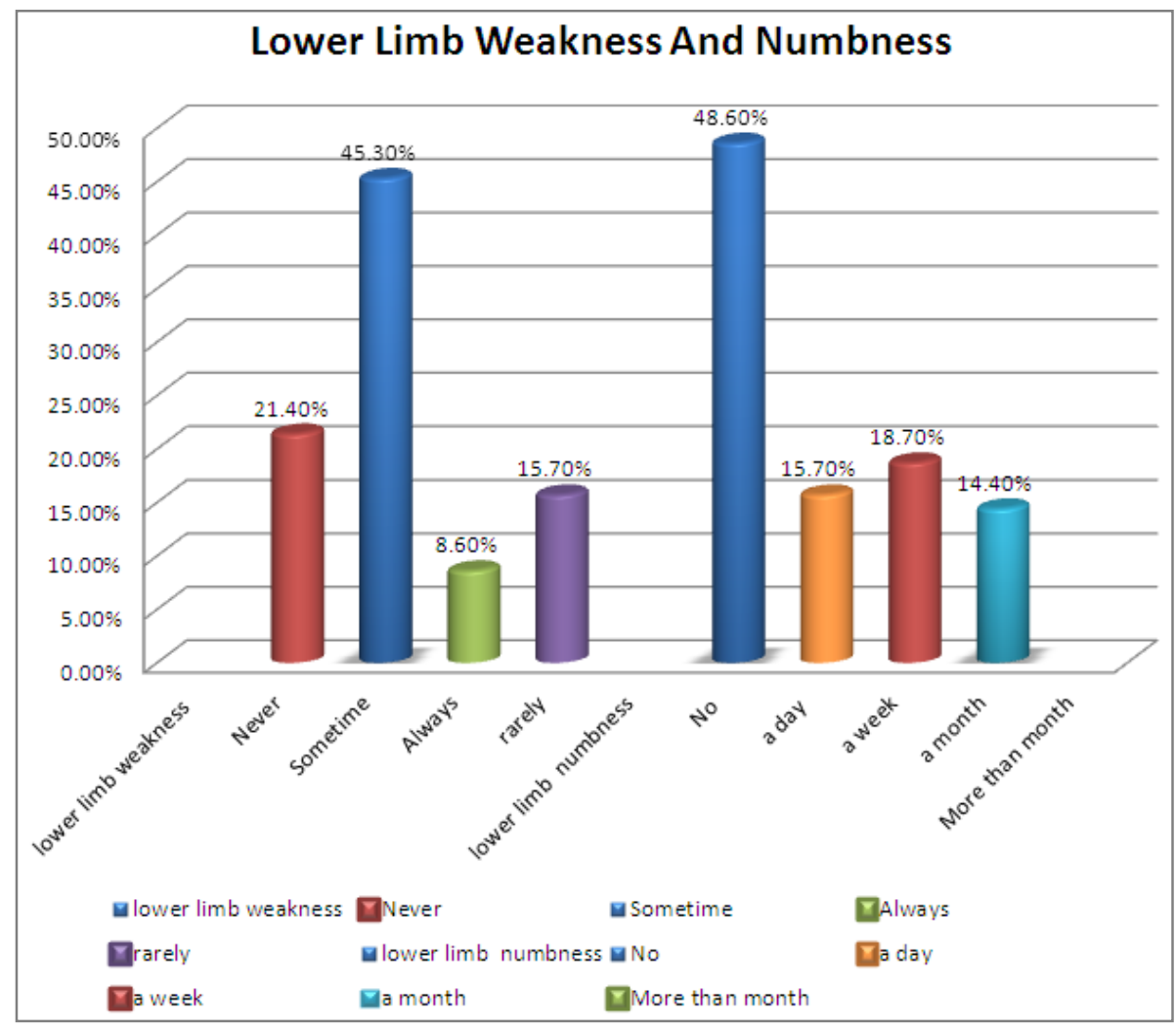

Figure 4: Lower limb weakness and numbness

Figure (4) illustrated that, less than quarter of nurses (21.4\%) never having LLW, less than half $(45.3 \%)$ some time, $(8.6 \%)$ always, less than quarter $(15.7 \%)$ rarely. Less than half $(48.6 \%)$ haven't numbness, less than quarter $(15.7 \%)$ a day, less than quarter $(18.7 \%)$ a week, $(14.4 \%)$ a month, and $(2.9 \%)$ experience numbness for more than month.

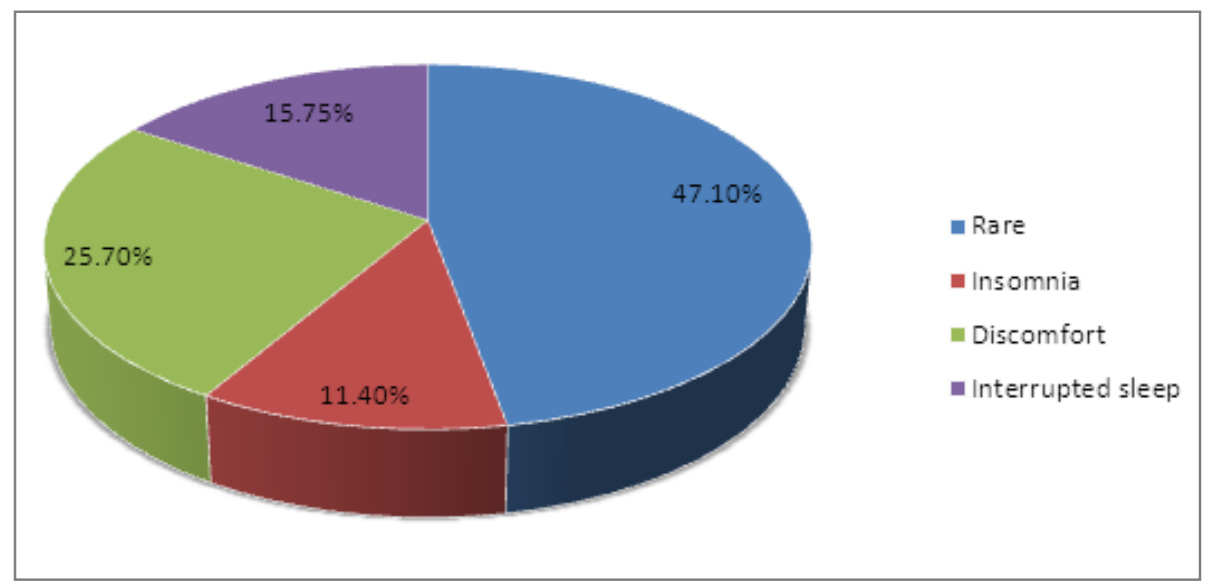

Figure 5: Sleeping disturbances:

Figure (5) showed that, less than half (47.1\%) of nurses rarely complaining from Sleeping disturbances, (11.4\%) having Discomfort, quarter of nurses (25.7\% )experience discomfort, and $(15.7 \%)$ having Interrupted sleep. 
Table 3: Frequency percentage of nursing presented to previous accident:

\begin{tabular}{|l|l|l|}
\hline Previous accident & Frequency & Valid percent \\
\hline Never & 55 & $78.6 \%$ \\
\hline Fall & 9 & $12.9 \%$ \\
\hline Motor vehicle accident & 5 & $7.1 \%$ \\
\hline fight & 1 & $1.4 \%$ \\
\hline Total & 70 & $100.0 \%$ \\
\hline
\end{tabular}

Table (3) showed that most of study group (78.6\%) never had previous accident, (12.9\%) had fall, (7.1\%) had Motor vehicle accident, and (1.4\%) been through fight.

Table 4: Frequency percentage of nursing seeking a doctor advice:

\begin{tabular}{|l|l|l|}
\hline Nurses seek doctor advice & Frequency & Valid percent \\
\hline Never & 43 & $61.4 \%$ \\
\hline Sometime & 11 & $15.7 \%$ \\
\hline Always & 5 & $7.1 \%$ \\
\hline Rarely & 11 & $15.7 \%$ \\
\hline Total & 80 & $100.0 \%$ \\
\hline
\end{tabular}

Table (7) showed that, number of nurses seeking doctor advice were $(61.4 \%)$ never,( $15.7 \%)$ sometime, (7.1\%) always, and ( $15.7 \%)$ rarely seeking doctor advice.

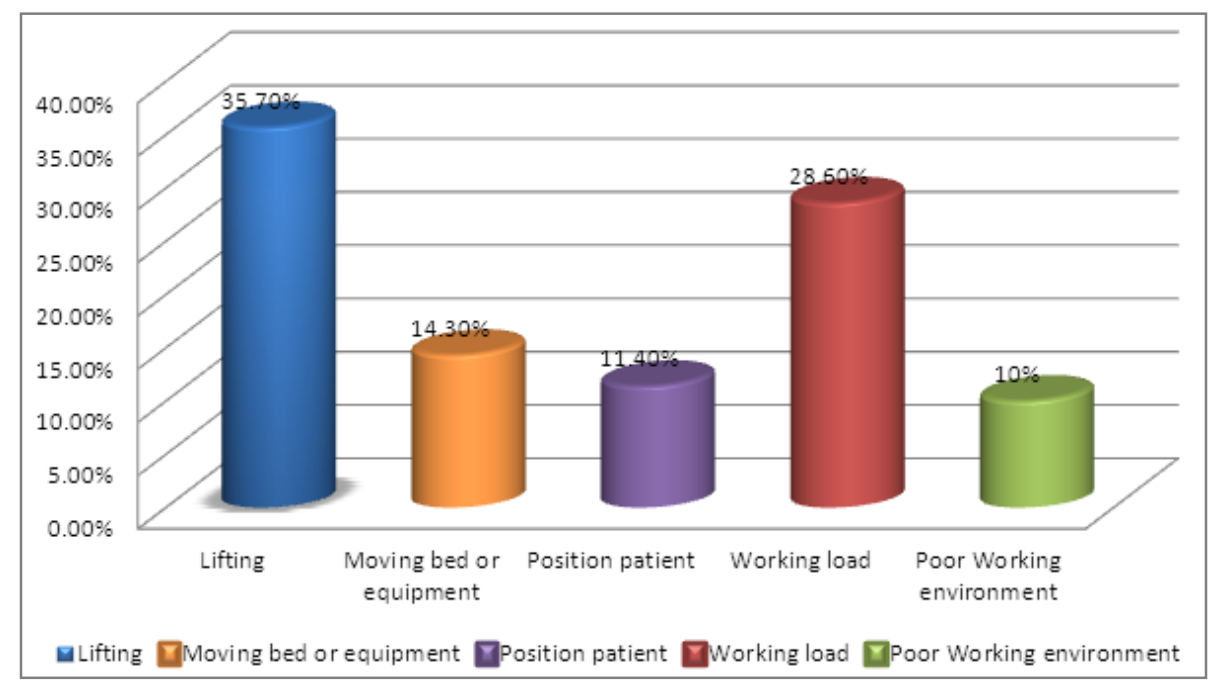

Figure 6: Nursing Concept Regarding Factors Contributing Their LBP:

Figure (6) showed that, about third of nurses (35.7\%) report that lifting is major factor of their LBP, quarter (14.3\%) moving bed or equipment, less than quarter (11.4\%) position patient, less than third $(28.6 \%)$ working load, and $10 \%$ report Poor working environment. 
Table 5: Frequency percentage of nurse's comment about effects caused by their LBP

\begin{tabular}{|l|l|l|}
\hline nurses comment & Frequency & Valid percent \\
\hline $\begin{array}{l}\text { a-restriction of activity and } \\
\text { movement }\end{array}$ & 45 & $64.3 \%$ \\
\hline b-taking many days off & 12 & $17.1 \%$ \\
\hline c-thinking to leave nursing & 7 & $10 \%$ \\
\hline $\begin{array}{l}\text { d-restriction of activity, movement, } \\
\text { taking many days off }\end{array}$ & 6 & $8.6 \%$ \\
\hline Total & 70 & $100.0 \%$ \\
\hline
\end{tabular}

Table (5) showed that, almost study group64.3\% comment that they have restriction of activity and movement, $17.1 \%$ they are taking many days off, while $8.6 \%$ having both effect, $10 \%$ thinking to leave nursing.

Table 6: Frequency percentage of nurses who reported occurs of LBP related to duty:

\begin{tabular}{|l|l|l|}
\hline Occurs of LBP relate to duty & Frequency & Valid percent \\
\hline a- pre on to post duty & 8 & $4.3 \%$ \\
\hline d- on duty & 20 & $28.6 \%$ \\
\hline c-on to post duty & 9 & $12.9 \%$ \\
\hline e- post duty & 33 & $47.1 \%$ \\
\hline Total & 70 & $100.0 \%$ \\
\hline
\end{tabular}

Table (6) showed that, (4.3\%) of nurses experience LBP pre on to post duty, less than third (28.6\%) on duty only, (12.9\%) on to post duty, and less than half (47.1\%) post duty.

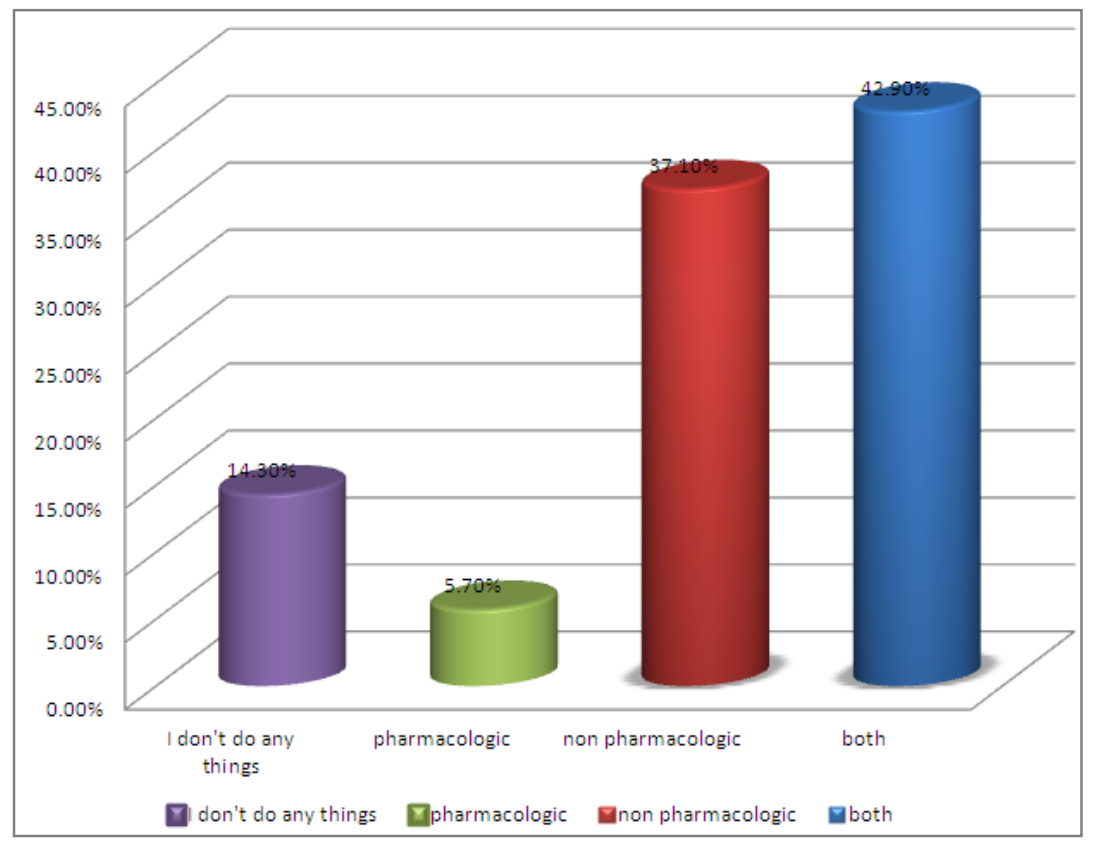

Figure 7: Management method of LBP

Figure (7) showed that, $14.3 \%$ of nurses complaining from LBP do not do any things to relieve pain, 5.7\% uses pharmacologic method while more than third $37.1 \%$ used non pharmacologic method, but less than half of complaining nurses used both method $(42.9 \%)$ 


\section{DISCUSSION}

Nurses, as professionals, have serious incidents of occupational LBP and traumas in the lumbar area, as their profession is unique with heavy emotional and physical work, and are exposed to a combination of mechanical and psychosocial stress at work.

The study reveal that, The percentage of low back pain found to be common among most of the study group 70 out of 80 (male 15 and female 65 ) was (87.5\%) of nurses recently reported having low back pain similar result reported by (Sikiru and Hanifa) are found in study In Nigeria, the 12 month prevalence of LBP among nurses was $73.53 \%$, this is considered high and was in line with that reported by (Maul et al) The present study also concurs with the findings of (Hinmikaiye, C., and E. Bamishaiye) they reported that 57 (78.1\%) respondents experienced the first episode of back pain after commencing nursing.

The individual risk factors, gender, age, marital status, working hours, and smoking were examined. Significant differences were detected between the groups of gender for prevalence of LBP. Females displayed higher percentages of LBP prevalence in accordance with (Sikiru, L., \& Shmaila, H) studies, they reported LBP was more prevalent among female nurses (67.5\%) than the male nurses (32.5\%), In the current work, significant association was found between gender and prevalence of LBP. Generally, $15 \%$ of the total male reported LBP while $(85 \%)$ of the total female reported LBP. The reason for female preponderance in this study was unclear but it may be related to the anatomical, physiological and structural difference between males and female, There was not significant predictor for LBP in this present study regarding the bad behavior even smoking.

In addition to that, the present study reveal that, the participants who were complaining of pain reported that the degree were $(21.43 \%$ mild, $52.9 \%$ moderate, $15.7 \%$ sever pain) .with less than half experience it once a week and quarter of them daily and a few time a year. Results of Greek study done by (Spyropoulos, Panagiotis, et al) showed that the pain intensity at the time of the survey ranged from moderate to unbearable in $38 \%$ of the sufferers, whereas the majority (43\%) of the recurrent episodes lasted from one day to one week. This study also report the prevalence of symptoms of low back pain which were : Weakness, less than half (45.3\%) some time, $(8.6 \%)$ always, less than quarter (15.7\%) rarely, numbness less than quarter $(15.7 \%-18.7 \%)$ a day, and a week .pain interrupt her or his sleep half, (11.4\%) having Discomfort, quarter of nurses(25.7\% )experience discomfort, and (15.7\%) having Interrupted sleep. pain increase with standing 50\% pain increase with sitting $50 \%$.we don't found study to compare our result with its.

The organizational culture of the work unit has been shown to be related to the occurrence of LBP. Participants in this study believe that work load, contribute to LBP. This was important as the ability to pace oneself when working (i.e. not only the amount or urgency of the work) will help to minimize the risk of developing LBP. Work load (28.6\%), and a poor environment at work $(10 \%)$ were chosen by participants as being the relevant factors that contribute to LBP.

Lifting of patients (35.7\%) was identified as being the main patient care activity that could cause LBP. These included lifting heavy patients, repetitive lifting and lifting alone. The reasons why nurses tend to injure their backs during transfers include loss of balance (nurse and/or patient), no transfer device, sudden movement and a poor physical work environment. Positioning patients 
(11.4\%), in bed and washing patients were the other activities that were also regarded as high risk. This is supported by (Jensen et al, 2003). Who found that the frequency of positioning patients in bed also predicted the development of LBP. Respondents reported that less than half $(47.1 \%)$ the LBP occurs post duty while more than quarter $(28.6 \%)$ on duty, and (12.9\%) on to post duty This is supported by (Yassi, A., \& Lockhart, K,2013)Who found that the nursing duties are also associated with elevated risk development of LBP.

LBP that arises in nurses who perform patient care duties should be considered to be substantially related to the risks imposed by their work, unless the contrary is shown, respondents reported the negative effect their work schedule is having on them, they were allowed to make multiple choices, $(64.3 \%)$ reported that it makes them to restrict and limit their activities and movement for the day and even have to take many days off $(17.1 \%)$ or both $(8.6 \%)$. Treatment of back pain remains unsatisfactory as indicated $(14.3 \%)$ do not do any things, (37.1\%) of the respondents with back pain in this study took some rest to relieve their back pain while $(5.7 \%)$ take analgesics. $(42.9 \%)$ took both methods to relieve their back pain.

\section{CONCLUSIONS}

- The results of this study revealed a high incidence of low back pain among nurses at Almak Nimer hospital.

- The majority of nurses, (87.5\%), experience LBP on a regular basis, with reported moderate degree of pain, although females displayed higher percentages of LBP incidence.

- Many risk factors were identified, lifting, moving equipment, positioning of patients in bed, work load, pressure and a poor working environment were the most perceived workrelated risk factors for LBP.

- sleep disturbance, restrict activities and movement, taking many days off, thinking to leave nursing might be the most predisposed effect related to LBP.

\section{RECOMMENDATIONS}

By the hospital manger and head nurse have to:-

- A comprehensive policy guideline that will address the management of LBP amongst staff must be put in place and made available to staff. In addition a procedure needs to be developed that can provide guidance when incidents concerning LBP occur.

- Comprehensive back programs, including physical and psychological components, have to be developed in consultation with nursing staff and implemented for staff in the hospital. This programs can be both preventative and rehabilitative in nature.

- There should be regular change in all hospital departments this will reduce the burden of work, which will also reduce a patent source of job stress.

\section{REFERENCES}

[1] Brunner, Lillian Sholtis. Brunner \& Suddarth's textbook of medical-surgical nursing. Eds. Suzanne CO'Connell Smeltzer, et al. Vol. 1. Lippincott Williams \& Wilkins, 2010., second edition, (2010), page 2047- 2052. 
[2] Nettina, Sandra M., Anp-BC Msn, and Sandra M. Nettina. Lippincott manual of nursing practice. Lippincott Williams \& Wilkins, 2013. page 1084-1088.

[3] El-Najjar, A., et al. (2014). "Prevalence of low back pain in working nurses in Zagazig University Hospitals: an epidemiological study." Egyptian Rheumatology

[4] Hinmikaiye, C. and E. Bamishaiye (2012). "The Incidence of Low Back Pain among Theatre Nurses: A Case Study of University of Ilorin and Obafemi Awolowo University Teaching Hospital." International Journal of Nursing Science 2(3): 23-28.

[5] Keriri, H. M. (2013). "Prevalence and risk factors of low back pain among nurses in operating rooms, Taif, Saudi Arabia. " American Journal of Research Communication 2(6): 45-70.

[6] Sikiru L, Hanifa S. Prevalence and risk factors of low back pain among nurses in a typical Nigerian hospital. African Health Sciences. 2010;10(1):26-30.

[7] Maul H, Laubli T, Klipstein A, Krueger H. Course of low back pain among nurses: a longitudinal study across eight years. Occupational and Environmental Medicine. 2003;60:497-503.

[8] Sikiru L, Shmaila H. Prevalence and risk factors of low back pain among nurses in Africa: Nigerian and Ethiopian specialized hospitals survey study. East Afr J Public Health. 2009; $6(1): 22-5$.

[9] Jensen, Jette N., et al. "The greatest risk for low-back pain among newly educated female health care workers; body weight or physical work load?." BMC musculoskeletal disorders 13.1 (2012): 87.

[10] Hinmikaiye, C., and E. Bamishaiye. "The Incidence of Low Back Pain among Theatre Nurses: A Case Study of University of Ilorin and Obafemi Awolowo University Teaching Hospital." International Journal of Nursing Science 2.3 (2012): 23-28.

[11] bing Yip, Yin. "A study of work stress, patient handling activities and the risk of low back pain among nurses in Hong Kong." Journal of advanced nursing 36.6 (2001): 794-804.

[12] Yassi, Annalee, and Karen Lockhart. "Work-relatedness of low back pain in nursing personnel: a systematic review." International journal of occupational and environmental health 19.3 (2013): 223-244

[13] http://en.wikipedia.org/wiki/Low_back_pain access in 20/5/2015, at 11:30AM.

[14] http://www.spine-health.com/conditions/lower-back- pain/lower-back-pain-symptomsand-causes access in 15/5/2015, at 10:15pM. Written by Peter F. Ullrich, Jr., MD.

[15] http://www.emedicinehealth.com/back_pain_health/page3_em.htm\#low_back_pain_symp toms Medical Author: William C. Shiel Jr., MD, FACP, FACR access in 15/5/2015, at 10:15pM 